DOI:

УДК $630 * 32: 330.332 .21$

ОЦЕНКА ТЕХНОЛОГИЧЕСКИХ ПРОЦЕССОВ ЛЕСОЗАГОТОВИТЕЛЬНЫХ ПРЕДПРИЯТИЙ

кандидат технических наук, доцент А. П. Мохирев ${ }^{1}$

кандидат сельскохозяйственных наук, доцент Е. В. Горяева ${ }^{2}$

кандидат экономических наук С. О. Медведев ${ }^{1}$

1 - Лесосибирский филиал ФГБОУ ВО «Сибирский государственный аэрокосмический университет имени академика М.Ф. Решетнева», г. Лесосибирск, Российская Федерация

2 - ФГАОУ ВО «Сибирский федеральный университет», г. Красноярск, Российская Федерация

В современных условиях предприятий лесной промышленности одной из актуальных проблем является проблема снижения себестоимости продукции. Рост цен на энергоресурсы, машины и оборудование, значительно превышающий рост стоимости товарной продукции лесопромышленных предприятий снижает эффективность производства. Разнообразие предлагаемых лесозаготовительных технологий и систем машин позволяет подбирать соответствующие природнопроизводственным условиям заготовки. Однако при их формировании не всегда используется логически обоснованная методика. В рамках данных исследований на примере лесозаготовительных участков (ЛЗУ) одного из крупнейших лесопромышленных предприятий РФ, расположенных на территории Нижнего Приангарья, проанализирована эффективность различных технологических процессов лесосечных работ. В результате исследования можно сделать следующие выводы. На лесозаготовках $3 \mathrm{AO}$ «Новоенисейский ЛХК» используются технологии с трелевкой деревьев, обрезкой сучьев и раскряжевкой на погрузочном пункте, вывозкой древесины в виде сортиментов. Машинизированными технологиями заготавливается 94 \% объема древесины. Процент использования расчетной лесосеки варьируется от 20 до 58 \%. Лесозаготовительный процесс организован по трем технологиям лесозаготовок: - валочно-пакетирующая машина (ВПМ) + пакетоподборщик (ПП) + сучкорезно-раскряжевочная машина (СРМ); - ВПМ + ПП+ бензопила (б/п); - б/п + ПП + б/п. Поскольку на валке и трелевке используют различные марки машин, то в результате сформировались четыре системы лесозаготовительных машин. Сменная производительность ВПМ практически одинакова во всех технологических цепочках, однако, производительность б/п на валке ниже в 15 раз. Сменная производительность ПП на трелевке деревьев варьируется в больших пределах в зависимости от технологии и используемой техники. Это свидетельствует о неэффективной организации работы машин на этой операции. В целом сменная выработка на обрезке сучьев и раскряжевке значительно ниже производительности машин на других операциях. За счет этого сменная производительность всей бригады снижена. Наиболее эффективная технология лесозаготовок с использованием ВПМ и трелевочных тракторов John Deer и Caterpillar. Система машин на базе тракторов Caterpillar показывает хорошие характеристики в различных природно-климатических условиях. Результаты оценки эффективности технологий и используемых вариантов систем лесозаготовительных машин по исследуемому предприятию показали, что для текущей оценки эффективности технологий может быть использован показатель величины производственно-экономических показателей.

Ключевые слова: эффективность, система машин, технологический процесс, технология лесозаготовок, технологическая цепочка, себестоимость лесозаготовок, оценка технологии

\title{
ESTIMATION OF TECHNOLOGICAL PROCESSES OF LOGGING ENTERPRISES
}

$\mathrm{PhD}$ in Engineering, Associate Professor A. P. Mokhirev ${ }^{1}$

$\mathrm{PhD}$ in Engineering, Associate Professor E. V. Goryaeva ${ }^{2}$

$\mathrm{PhD}$ in Economical Sciences S. O. Medvedev ${ }^{1}$

1 - Lesosibirskiy Branch of the Reshetnev Siberian State Aerospace University, Lesosibirsk, Russian Federation

2 - Federal State Autonomous Educational Institution of Higher Education «Siberian Federal University», Krasnoyarsk, Russian Federation

\section{Abstract}

In modern conditions for the forest industry one of the most pressing problems is the problem of reducing costs of production. Rising prices for energy resources, machinery and equipment, significantly exceeding the growth in the value of marketable 
production of timber industry enterprises reduced production efficiency. The variety of offered harvesting technologies and systems of machines allows to select machines, corresponding to natural and production conditions of logging schemes. However, with their formation, logically based procedure is not always used. Within the framework of these studies, on the example of logging sites (LS) of one of the largest forest industry enterprises of the Russian Federation, located in the Lower Priangarie, the effectiveness of various technological processes of logging operations have been analyzed. As a result of research the following conclusions can be made. On logging sites of the "Novoyeniseisk Forest Chemical Complex", technology for skidding trees, tree trimming and bucking at the loading site, wood removals in the form of log assortments is used. Ninety four percent of the logging volume of timber is harvested by the mechanized technologies. The percentage of use of annual allowable cutting varies from 20 to $58 \%$. Forest harvesting process is organized in three harvesting technologies: - feller buncher (FB) + packetport (PP) + tree trimming-bucking machine (TTBM); - FB + PP + chainsaw (c/s); - c/s + PP + c/s. As in the felling and skidding operations different brands of machines are used, the result is a formed system of four forest harvesting machines. Shift efficiency of FB is almost the same in all production chains; however, efficiency of $\mathrm{c} / \mathrm{s}$ in logging operations is lower in 15 times. Shift efficiency of PP in skidding trees varies, depending on the used technology and machinery. This demonstrates the inefficient organization of the machinery work in this operation. In general, shift output in tree trimming and bucking is significantly lower than efficiency in other operations. Due to this, shift efficiency of the entire team has been reduced. The most efficient is technology of harvesting using John Deer and Caterpillar FB skidders. The system of machines based on Caterpillar tractors shows good efficiency in various natural and climatic conditions. The results of evaluation of the effectiveness of technologies and used variants of logging machines systems in the investigated enterprise, has shown that for current evaluation of technology effectiveness, production and economic indicators can be used.

Keywords: effectiveness, system of machines, technological process, technology of harvesting, technological chain, cost of logging, assessment of technology.

Лесопромышленный комплекс Российской Федерации представляет собой многоотраслевое хозяйство. Все его составляющие технологически связаны между собой на основе заготовки древесины и ее переработки на деревообрабатывающих, целлюлознобумажных и лесохимических предприятиях [12].

Главной задачей деятельности лесопромышленных предприятий является получение наибольшей прибыли от заготовленной древесины.

Лесозаготовительная промышленность является первой и одной из самых трудоемких в лесопромышленном комплексе. В настоящее время лесозаготовительная промышленность наименее прибыльна [1]. Низкая эффективность работы лесозаготовительных предприятий отрицательно сказывается на работе всего лесопромышленного комплекса. Поэтому повышение эффективности лесозаготовительной деятельности первоочередная задача в деле становления лесопромышленного комплекса [2].

Для лесной промышленности самыми крупными затратами являются расходы на заготовку и транспортировку древесины включая затраты на топливо и энергию. Суммарная величина этих затрат достигает 40-45 \% общего объема затрат. Таким образом, сниже- ние себестоимости производства продукции лесозаготовок - одна из главных задач, решение которой благотворно скажется на работе всего лесопромышленного комплекса $[4,11]$.

Целью настоящих исследований является проведение оценки эффективности различных технологических процессов лесозаготовок.

Большое значение на эффективность технологического процесса влияет применяемая система машин [10].

Формирование эффективной технологической цепочки и системы машин следует производить, учитывая целый набор характеризующих его показателей $[5,7]$. Так, экономическая эффективность может быть оценена показателями производительности и себестоимости продукции. Оценивая технологический процесс по экологическим критериям можно отнести сохранность подроста, повреждения почво-грунтов, повреждения оставляемых деревьев и ряд других.

В качестве дополнительных критериев можно оценить показатели качества готовой продукции. В современных экономических условиях на данные критерии обращают все больше внимание [3].

В последние годы повышенное внимание уде- 
ляется созданию комфортных и безопасных условий труда рабочих на лесосечных работах.

Таким образом, оценка эффективности и выбор наиболее приемлемого для конкретных природнопроизводственных условий технологического процесса должны осуществляться комплексно на основе целого ряда показателей: экономических, экологических, эргономических, а также качества получаемых лесоматериалов [8].

Однако, оценка большого количества показателей, влияющих на эффективность технологического процесса трудозатратна.

Оценку эффективности систем машин и механизмов предлагается производить путем сравнения следующих основных технико-экономических показателей по каждому варианту систем машин и механизмов: производительности труда (П удельных капитальных вложений $\left(\mathrm{K}_{\text {уд }}\right.$, руб./ $\left.\mathrm{M}^{3}\right)$, удельных эксплуатационных затрат (Эуд, руб./м³). Могут быть использованы и другие технико-экономические показатели: удельная себестоимость $\left(\mathrm{C}_{\mathrm{y}}\right.$, руб./ $\left.\mathrm{M}^{3}\right)$, удельная энергоемкость $\left(\mathrm{E}_{\mathrm{y}}, \mathrm{KB} / \mathrm{M}^{3}\right)$ и др. Все эти показатели рассчитываются по каждому варианту. При этом соблюдается сопоставимость вариантов, что возможно, когда конечный вид получаемой продукции один и тот же во всех вариантах, похожи природнопроизводственные условия [9].
Исследования проводились на лесозаготовительных участках ЗАО «Новоенисейский ЛХК». Арендные территории расположены в различных лесничествах Нижнего Приангарья. Они отличаются разнообразием природно-производственных условий [6].

ЗАО «Новоенисейский ЛХК» использует различные технологии лесозаготовительных работ: ручную валку деревьев, сортиментную технологию заготовки с трелевкой деревьями импортными лесозаготовительными комплексами производства John Deere, Caterpillar, Tigercat, Ponsse, Logmax. В подборе технологических цепочек и систем машин на лесозаготовительных участках не просматривается логически обоснованной методики, а себестоимость лесозаготовок варьируется в значительном диапазоне - 800-1900 рублей за $1 \mathrm{~m}^{3}$. Поэтому вопрос подбора эффективных технологий на научной основе и снижения себестоимости лесозаготовок очень актуален для предприятия в связи со сложившейся экономической ситуацией в стране.

Используемые в лесозаготовительных участках системы машин и природно-производственные условия работы представлены в табл. 1.

Наиболее распространенные технологии - с использованием многооперационных валочнопакетирующих машин и трелёвочных машин (пакетоподборщиков).

Таблица 1

Исходные данные для анализа технологий

\begin{tabular}{|c|c|c|c|c|c|}
\hline ЛЗУ & Система машин & $\begin{array}{c}\text { Среднее рас- } \\
\text { стояние трелев- } \\
\text { ки, км }\end{array}$ & $\begin{array}{c}\text { Среднее рас- } \\
\text { стояние вывоз- } \\
\text { ки, км }\end{array}$ & $\begin{array}{c}\text { Средний } \\
\text { объем хлы- } \\
\text { ста, } \text { м }^{3}\end{array}$ & $\begin{array}{l}\text { Годовой объем } \\
\text { лесозаготовок, } \text { м }^{3}\end{array}$ \\
\hline Назимовский & $\begin{array}{c}\text { ВПМ John Deer+ПП John Deer+ СРM } \\
\text { Ponsse }\end{array}$ & 0,3 & 70 & 0,7 & 78000 \\
\hline \multirow[t]{2}{*}{ Усть-Кемский } & б/п Stihl+ТЧ ТТ-4+ б/п Stihl & 0,2 & 180 & 0,6 & 39640 \\
\hline & $\begin{array}{c}\text { ВПМ Caterpillar+ } \\
\text { ПП Caterpillar+ CPM Ponsse }\end{array}$ & 0,2 & 180 & 0,6 & 158557 \\
\hline Мотыгинский & ВПМ Caterpillar+ ПП+ СРM Ponsse & 0,3 & 140 & 0,6 & 81000 \\
\hline Нижнетерянский & $\begin{array}{c}\text { ВПМ John Deer + } \\
\text { ПП John Deer+б/п Stihl }\end{array}$ & 0,4 & 100 & 0,5 & 83000 \\
\hline Гремучинский & $\begin{array}{c}\text { ВПМ John Deer+ } \\
\text { ПП John Deer+ CPM Ponsse }\end{array}$ & 0,5 & 150 & 0,7 & 167000 \\
\hline Хребтовский & $\begin{array}{c}\text { ВПМ John Deer+ } \\
\text { ПП John Deer + б/п Stihl }\end{array}$ & 0,4 & 100 & 0,7 & 99000 \\
\hline
\end{tabular}

Примечание: сокращения в таблице ВПМ - валочно-пакетирующая машина, ПП - пакетоподборщик, ТЧ - трелевочный трактор с канатно-чокерным оборудованием, СРМ - сучкорезно-раскряжевочная машина, б/п - бензопила 
Во всех рассматриваемых технологиях используется трелевка деревьев, разделка которых производится на погрузочном пункте, где формируется продукция готовая к вывозке - сортименты.

В целом на предприятии используется 4 технологические цепочки (валка- трелевка деревьев обрезка сучьев и раскряжевка на сортименты):

1 ВПМ John Deer - ПП John Deer-CPM Ponsse;

2 ВПМ John Deer - ПП John Deer - б/п Stihl;

3 ВПМ Cat - ПП Cat-CPM Ponsse;

4 б/п Stihl - ТЧ ТТ-4 - б/п Stihl.

Производительность трелевочных машин варьируется в зависимости от технологий. Однако если сравнивать одну систему машин при работе в разных условиях, то трелевочные машины показывают одинаковую производительность, несмотря на разницу в лесоводственных и природно-экологических условиях. В Мотыгинском, Нижнетерянском и Хребтовском ЛЗУ выработка валочных и трелевочных машин одинакова и составляет 150-196 м 3 в смену. Если рассматривать первую технологическую цепочку в Гремучинском ЛЗУ, то производительность машин на всех операциях выше, по сравнению с другими технологическими цепочками.

Сменная выработка при ручной технологии в зависимости от операции ниже на 66-90 \% по сравнению с машинными технологиями (рис. 1). Однако, производительность механизмов при этой технологии

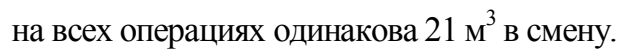

Одно из условий составления эффективной технологической цепочки - это одинаковая производительность машин на всех операциях. Этому условию отвечает только технология №4. Сравним максимальную (ее показывают валочные машины) и минимальную (ее показывают сучкорезнораскряжовочные машины) выработки по технологиям (рис. 2). Из машинных технологий наименьшая разница между максимальной и минимальной выработкой машин, входящих в технологическую цепочку 3-85 \%. Это говорит о неэффективном подборе машин, в результате, валочные машины используются неэффективно, а сучкорезнораскряжовочные машины перегружены.

Эффективность применения той или иной технологии определяется множеством техникоэкономических показателей, среди которых можно выделить эксплуатационные затраты. При оценке по экономическим элементам затраты группируют в соответствии с их экономическим содержанием:

-оплата труда производственных рабочих;

-отчисления на социальные нужды;

-амортизация используемых машин и механизмов;

-материальные затраты (включая затраты на топливо-смазочные материалы, ТОи Р);

-прочие затраты,

-включая лизинговые платежи, а также износ бензиномоторных пил, резины, затраты на тросы, блоки и пр.

Сравнение общих затрат (рис. 3) и себестоимости $1 \mathrm{~m}^{3}$ заготовки древесины (рис. 4) по технологиям показывает, что наиболее затратна технология № 1 в Гремучинском ЛЗУ, а наиболее выгодна с экономической точки зрения технология №3 в

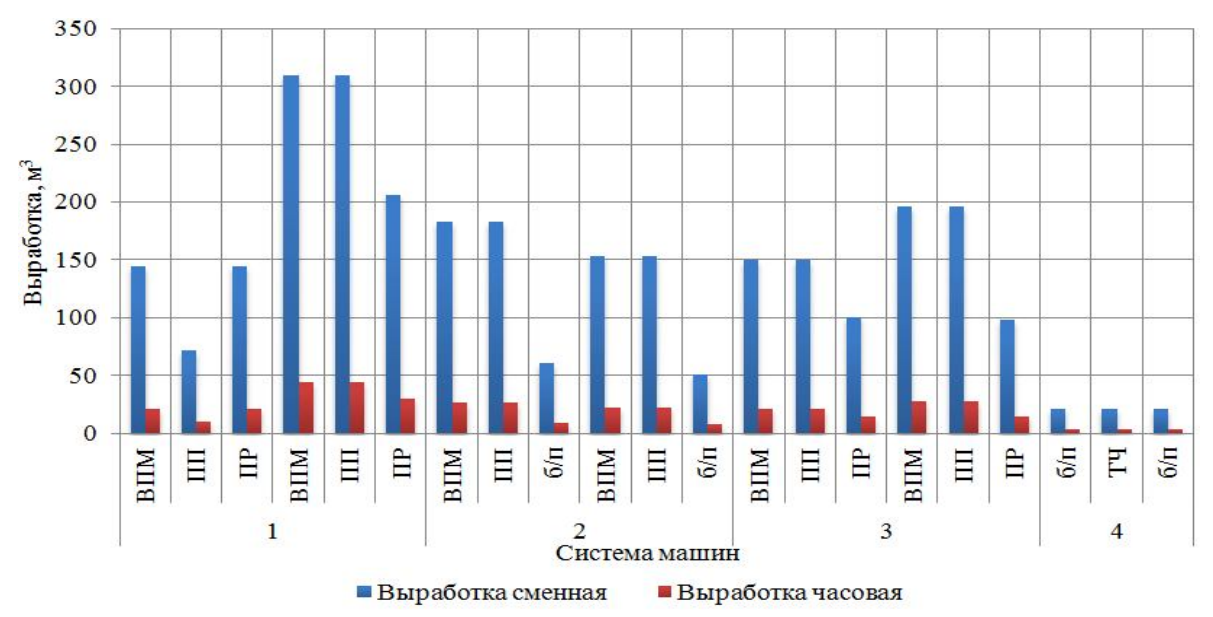

Рис. 1. Сравнение сменной и часовой выработки механизмов по технологиям 


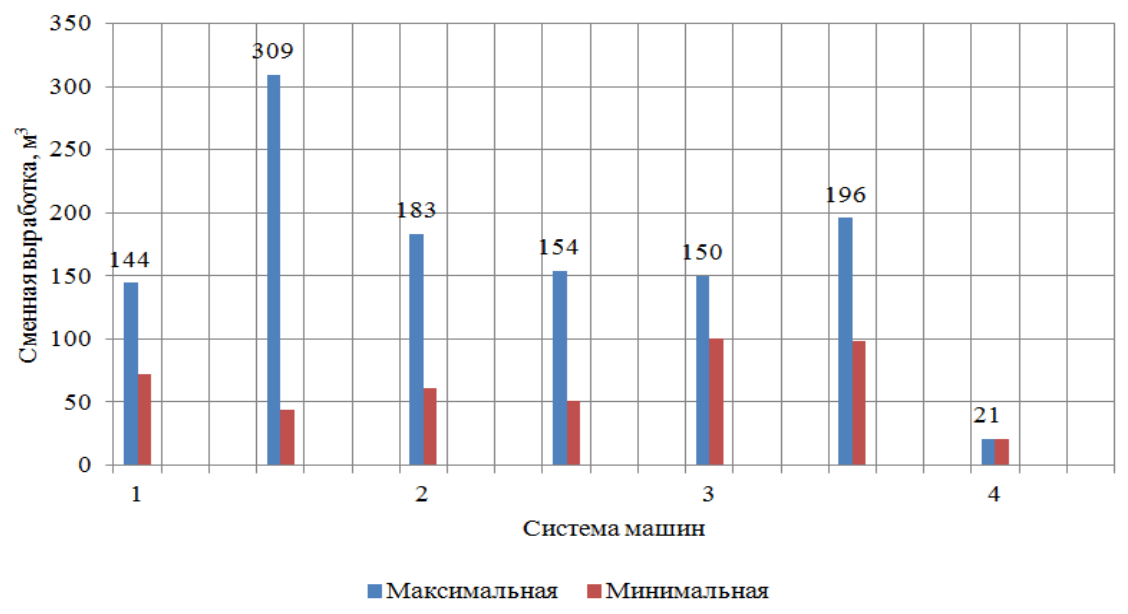

Рис. 2. Сравнение максимальной и минимальной выработки по технологиям

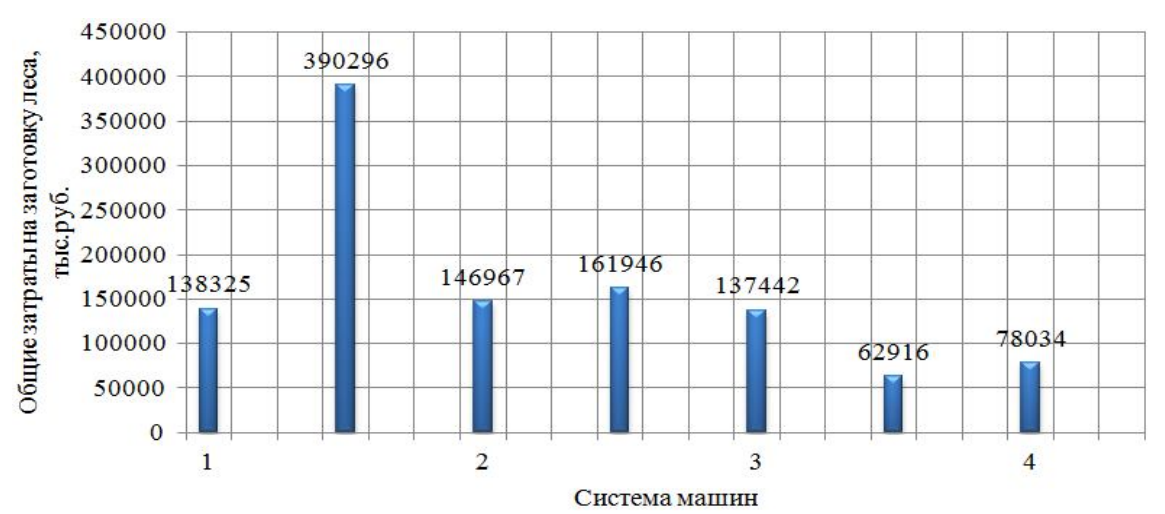

Рис. 3. Общие затраты на заготовку леса в 2014-2015 году по рассматриваемым технологиям

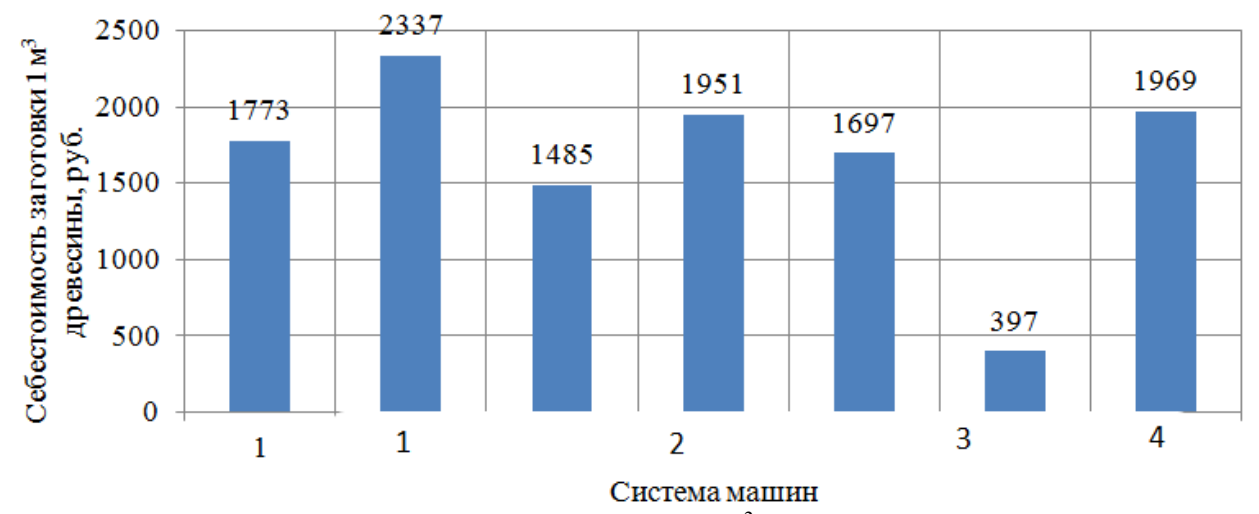

Рис. 4. Сравнение себестоимости заготовки $1 \mathrm{~m}^{3}$ древесины по системам машин

Усть-Кемском ЛЗУ. В целом, технологические цепочки № 2 и 3 имеют хорошие результаты по всем показателям, но технология №3 в Усть-Кемском ЛЗУ дает наилучшие характеристики.

Анализ общих затрат по статьям расходов (рис. 5) показывает, что при одной и той же технологии в разных условиях процентное соотношение по статьям затрат неодинаковое. Так в Гремучинском ЛЗУ наи- большая статья затрат - это услуги подрядчиков, так же велики затраты на покупку сырья (остальные ЛЗУ сырье не приобретают) и заработную плату, что и делает эту технологии самой затратной из рассматриваемых. Во всех ЛЗУ, пользующихся услугами подрядчиков, себестоимость заготовки $1 \mathrm{~m}^{3}$ древесины значительно выше, по сравнению с ЛЗУ, заготавливающие древесину своими силами. 


\section{Лесоинженерное дело}

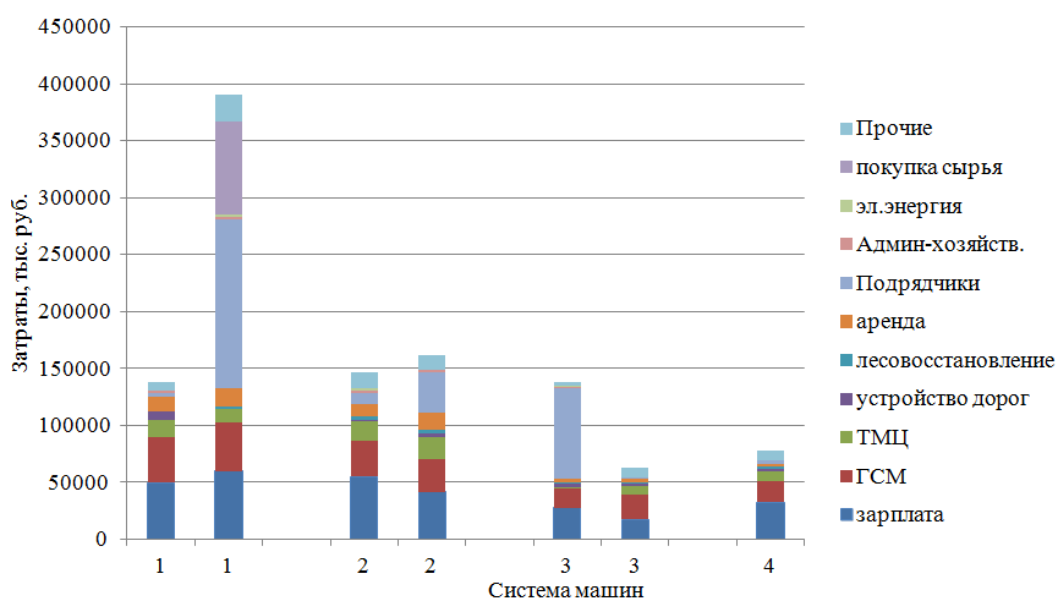

Рис. 5. Распределение себестоимости лесозаготовок по статьям затрат и технологиям

В технологиях №1 и 2 общие затраты на оплату труда значительно выше по сравнению с технологией №3 и 4, разница составляет 7-70\%. При этом состав бригад в машинизированных технологиях одинаков.

Анализ показал, что наиболее эффективная система лесозаготовительных машин №1 и 3. Это машинизированные технологии, в которой используются комплексы компаний John Deer и Caterpillar. Система машин № 3 показывает хорошие характеристики в различных природно-климатических условиях. Система машин №1 показывает неоднозначные результаты в различных природно-климатических условиях.

Система машин №2 с обрезкой сучьев и раскряжевкой бензопилами средней эффективности. На валке и трелевке деревьев используются комплексы компании John Deer.

Механизированная технология №4, используемая в Усть-Кемском ЛЗУ работает с самой низкой эффективностью. Этой технологией заготавливается наименьший объем древесины при низкой производительности механизмов и высоких затратах на производство. Следует заметить, что в этом ЛЗУ используют две технологии - наиболее эффективную и наименее эффективную.

Обобщая проведенные исследования можно сделать следующие выводы:

1 На лесозаготовках ЗАО «Новоенисейский ЛХК» используются сортиментные технологии с трелевкой деревьев и обрезкой сучьев и раскряжевкой на погрузочном пункте, вывозка производится сортиментами. Машинизированными технологиями заготавли- вается 94 \% объема древесины.

2 Во всех ЛЗУ имеется потенциал к увеличению объема лесозаготовок. Процент использования расчетной лесосеки варьируется от 20 до 58 \%.

3 Лесозаготовительный процесс организован по трем технологиям лесозаготовок:

- валочно-пакетирующая машина + пакетоподборщик + сучкорезно-раскряжевочная машина;

- валочно-пакетирующая машина + пакетоподборщик+ бензопила;

- бензопила + пакетоподборщик + бензопила.

Поскольку на валке и трелевке используют различные марки машин, то в результате сформировались четыре системы лесозаготовительных машин;

4 Сменная производительность валочнопакетирующих машин практически одинакова во всех технологических цепочках, однако, производительность бензопил на валке ниже в 15 раз.

5 Сменная производительность пакетоподборщиков на трелевке деревьев варьируется в зависимости от технологии. Пакетоподборщики John Deer показывают сменную выработку от 72 до 309 м $^{3}$, тогда как Caterpillar демонстрируют более стабильную работу. Их выработка составляет 150-196 м³ в смену. Тречевочный трактор ТТ-4 при ручной технологии наименее эффективен.

6 Сменная производительность процессоров с харвестерной головкой варьируется от 51 до $206 \mathrm{~m}^{3}$. Это свидетельствует о неэффективной организации работы машин на этой операции. В целом сменная выработка на обрезке сучьев и раскряжевке значительно ниже производительности машин на других операци- 
ях. За счет этого сменная производительность всей бригады снижена. Это самое узкое звено в технологической цепочке.

7 Анализ общих эксплуатационных затрат на лесозаготовки показал, что использование услуг подрядных организаций и покупка сырья значительно увеличивает себестоимость продукции.

Наиболее экономичная система машин №3, наименее эффективна с экономической точки зрения технология с применением бензопил на валке деревьев. Технология №1 показывает разные результаты в раз- личных условиях. Так в Гремученском ЛЗУ себестоимость $1 \mathrm{~m}^{3}$, заготовленного технологией №1 выше, чем при технологии с использованием бензопил на $17 \%$, тогда как в Назимовском ЛЗУ этот показатель чуть выше, чем у технологий № 1 и №2.

Исследование выполняется при поддержке РГНФ (грант № 15-12-24003) и КГАУ «ККФПНиНТД» (проект «Разработка системы управления лесопромышленным предприятием в современных условиях»).

\section{Библиографический список}

1. Gerasimov, Y. Industrial round-wood losses associated with harvesting systems in Russia [Text] / Y. Gerasimov, A. Seliverstov // Croatian Journal of Forest Engineering. - 2010. Vol. 32. - no. 2. - pp. 111-126.

2. Gerasimov, Y. Industrial round-wood damage and operational efficiency losses associated with the maintenance of a single-grip harvester head model: a case study in Russia [Text] / Y. Gerasimov, A. Seliverstov, V. Syunev // Forests. - 2012. - Vol. 3. - no. 4. - pp. 864-880.

3. Gerasimov, Y. Development trends and future prospects of cut-to-length machinery [Text] / Y. Gerasimov, A. Sokolov, V. Syunev // Advanced Materials Research. - 2013. - Vol. 705. - pp. 468-473.

4. Spinelli, R. Cable logging contract rates in the alps: the effect of regional variability and technical constraints [Text] / R. Spinelli, N. Magagnotti, R. Visser, O. Thees, U.H. Sauter, N. Krajnc, C. Riond // Croatian Journal of Forest Engineering. - 2015. - T. 36. - no. 2. - pp. 195-203.

5. Крупко, А.М. Математические методы в обосновании эффективных режимов и параметров технологии заготовки и транспортировки биомассы дерева [Текст] : монография / А.М. Крупко, П.В. Будник // Петрозаводск.: Изд-во ПетрГУ, 2015. - 64 с.

6. Мохирев, А.П. Исследование специфики лесозаготовок в Красноярском крае [Текст] / А.П. Мохирев, П.Ф. Мохирев // Resources and Technology. - 2015. - Т. 12. - № 2. - С. 98-108.

7. Мохирев, А.П. Критерии оценки технологий лесозаготовительных производств [Электронный ресурс] / А.П. Мохирев, П.Ф. Мохирев // Инженерный вестник Дона. - 2015. - Т. 38. - № 4 (38). - С. 122. - Режим доступа: ivdon.ru/ru/magazine/archive/n4y2015/3318.

8. Сорокин, Д.А. Подходы к оценке экономической эффективности инвестиций в технологии лесоэксплуатации лесозаготовительных предприятий Среднего Приангарья [Текст] / Д.А. Сорокин, А.Н. Сухих // Лесотехнический журнал. - 2014. - Т. 4. - № 3 (15). - С. 331-339.

9. Сравнение технологий лесосечных работ в лесозаготовительных компаниях Республики Карелия [Текст] / В.С. Сюнёв [и др.]. - Петрозаводск: Изд-во ПетрГУ, 2008. - 127 с.

10. Шегельман, И.Р. Исследование направлений модернизации технологий и техники лесозаготовок [Электронный ресурс] / И.Р. Шегельман // Инженерный вестник Дона. - 2012. - Т. 20. - № 2. - С. 714-719. Режим доступа: ivdon.ru/ru/magazine/archive/n2y2012/866

11. Шегельман, И.Р. Ресурсосберегающие технологии на лесозаготовках. Терминология и направления проблемно-ориентированных исследований [Текст] / И.Р. Шегельман, О.Н. Галактионов, П.О. Щукин // Глобальный научный потенциал. - 2012. - № 10. - С. 89-93.

12. Шегельман, И. Комплексный анализ производственно-хозяйственной деятельности лесозаготовительных предприятий [Текст] / И. Шегельман, М. Рудаков, П. Мощевикин. - М.: Изд-во ПрофиКС, 2006. - 336 с. 


\section{References}

1. Gerasimov Y., Seliverstov A. Industrial round-wood losses associated with harvesting systems in Russia Croatian Journal of Forest Engineering, 2010, Vol. 32, no. 2, pp. 111-126.

2. Gerasimov Y., Seliverstov A., Syunev V. Industrial round-wood damage and operational efficiency losses associated with the maintenance of a single-grip harvester head model: a case study in Russia - Forests, 2012, Vol. 3, no. 4, pp. 864-880. doi: 10.3390/f3040864

3. Gerasimov Y., Sokolov A., Syunev V. Development trends and future prospects of cut-to-length machinery Advanced Materials Research, 2013, Vol. 705, pp. 468-473. doi: 10.4028/www.scientific.net/AMR.705.468

4. Spinelli R., Magagnotti N., Visser R., Thees O., Sauter U.H., Krajnc N., Riond C. Cable logging contract rates in the alps: the effect of regional variability and technical constraints - Croatian Journal of Forest Engineering, 2015, Vol. 36, no. 2, pp. 195-203.

5. Krupko A.M., Budnik P.V. Matematicheskie metody v obosnovanii effektivnykh rezhimov i parametrov tekhnologii zagotovki i transportirovki biomassy dereva [Mathematical methods to study the effective modes and parameters of the technology of harvesting and transportation of biomass wood] Petrozavodsk, 2015, 64 p. (In Russian).

6. Mokhirev A.P., Mokhirev P.F. Issledovanie spetsifiki lesozagotovok v Krasnoyarskom krae [Study of the specifics of logging in Krasnoyarsk region] Resources and Technology, 2015, Vol. 12, no. 2, pp. 98-108. (In Russian). doi: 10.15393/j2.art.2015.3061

7. Mokhirev A.P., Mokhirev P.F. Kriterii otsenki tekhnologiy lesozagotovitel'nykh proizvodstv [Evaluation criteria of technologies for logging industries] Inženernyj vestnik Dona [Engineering journal of don]. 2015, Vol. 38, no. 4 (38), pp. 122. Available at: ivdon.ru/ru/magazine/archive/n4y2015/3318. (In Russian).

8. Sorokin D.A., Sukhikh A.N. Podkhody k otsenke ekonomicheskoy effektivnosti investitsiy v tekhnologii lesoekspluatatsii lesozagotovitel'nykh predpriyatiy Srednego Priangar'ya [Approaches to assessment of economic effectiveness of investments in technology in forest exploitation by logging companies of the Middle Angara region] Lesotekhnicheskii zhurnal, 2014, Vol. 4, no. 3 (15), pp. 331-339. (In Russian). doi: 10.12737/6312

9. Syunev V.S. Sokolov A.P., Konovalov A.P., Katarov V.K., Seliverstov A.A. Sravnenie tekhnologiy lesosechnykh rabot $v$ lesozagotovitel'nykh kompaniyakh Respubliki Kareliya [A comparison of the technology of logging operations the logging companies of the Republic of Karelia] Petrozavodsk, 2008, 127 p. (In Russian).

10. Shegelman I.R. Issledovanie napravleniy modernizatsii tekhnologiy i tekhniki lesozagotovok [The research directions of modernization of technologies and equipment of timber cuttings] Inženernyj vestnik Dona [Engineering journal of don]. 2012, Vol. 20, no. 2, pp. 714-719. Available at: ivdon.ru/ru/magazine/archive/n2y2012/866. (In Russian).

11. Shegelman I.R., Galaktionov O.N., Shchukin P.O. Resursosberegayushchie tekhnologii na lesozagotovkakh. Terminologiya i napravleniya problemno-orientirovannykh issledovaniy [Resource-saving technologies in logging. Terminology and directions of problem-oriented research] Global'nyy nauchnyy potentsial [The global scientific potential]. 2012, no. 10, pp. 89-93. (In Russian).

12. Shegelman I., Rudakov M., Moshchevikin P. Kompleksnyy analiz proizvodstvenno-khozyaystvennoy deyatel'nosti lesozagotovitel'nykh predpriyatiy [A comprehensive analysis of production and economic activities of logging companies] Moscow, 2006, 336 p. (In Russian).

\section{Сведения об авторах}

Мохирев Александр Петрович - доцент кафедры технологии лесозаготовительных и деревоперерабатывающих производств Лесосибирского филиала ФГБОУ ВО «Сибирский государственный аэрокосмический университет имени академика М.Ф. Решетнева», кандидат технических наук, доцент, г. Лесосибирск, Российская Федерация; e-mail: ale-mokhirev@yandex.ru.

Горяева Елена Владимировна - доцент кафедры автомобильных дорог и городских сооружений ФГАОУ ВО «Сибирский федеральный университет», кандидат сельскохозяйственных наук, доцент, г. Красноярск, Российская Федерация; e-mail: gor-elka@yandex.ru. 
Медведев Сергей Олегович - научный сотрудник Лесосибирского филиала ФГБОУ ВО «Сибирский государственный аэрокосмический университет имени академика М.Ф. Решетнева», кандидат экономических наук, г. Лесосибирск, Российская Федерация; e-mail: medvedev_serega@mail.ru.

\section{Information about authors}

Mokhirev Aleksandr Petrovich - Associate Professor of Technology of logging and wood processing industries Lesosibirskiy Branch of the Reshetnev Siberian State Aerospace University, PhD in Engineering, Associate Professor, Lesosibirsk, Russian Federation; e-mail: ale-mokhirev@yandex.ru.

Goryaeva Elena Vladimirovna - Associate Professor of department of highways and urban structures Federal State Autonomous Educational Institution of Higher Education «Siberian Federal University», PhD in Engineering, Associate Professor, Krasnoyarsk, Russian Federation; e-mail: gor-elka@yandex.ru.

Medvedev Sergey Olegovich - Researcher Federal State Autonomous Educational Institution of Higher Education «Siberian Federal University», PhD in Economical Sciences, Lesosibirsk, Russian Federation; e-mail: medvedev_serega@mail.ru.

DOI:

УДК $656 * 4$

\section{РАЗРАБОТКА МЕТОДИКИ И АЛГОРИТМА РЕШЕНИЯ ЗАДАЧИ БЕЗУБЫТОЧНОСТИ ЛЕСОПРОМЫШЛЕННОГО ПРОИЗВОДСТВА}

доктор технических наук, профессор С. И. Сушков ${ }^{1}$ доктор технических наук, профессор О. Н. Бурмистрова ${ }^{2}$ кандидат технических наук Ю. Н. Пильник ${ }^{2}$

1 - ФГБОУ ВО «Воронежский государственный лесотехнический университет имени Г.Ф. Морозова», г. Воронеж, Российская Федерация

2 - ФГБОУ ВПО «Ухтинский государственный технический университет», г. Ухта, Российская Федерация

Необходимыми условиями эффективности лесопромышленного производства является применение в управлении апробированных математических методов моделирования, с помощью которые можно увеличить производительность транспортных операций, сократить простои и неоптимальные сетевые перевозки лесных грузов, увеличить эффективность всего транспортно-технологического процесса в лесных предприятиях при освоении лесосырьевых баз и тронспортировки лесной продукции потребителям. Для эффективного использования экономико-математического подхода к решению сетевых транспортных потоков лесных грузов необходимо проводить анализ производственных процессов на всех фазах как производства, так и доставки лесной продукции от поставщиков к потребителям. Затруднения возникают при расчете безубыточности сетевых перевозок и определения рубежа, когда поставка лесных грузов оптимальна. Лучше всего это воспроизводится в виде графических инструментов для каждого конкретного случая доставки, позволяющих более оперативно определить объемы, затраты, прибыль от совершенной транспортной операции. Для сокращения времени составления графиков поставки разрабатывается методика расчета, алгоритм определения прибыльности данного рейса (сетевого взаимодействия). При этом данный подход может применяться на всех этапах планирования перевозочного процесса лесных грузов для принятия оптимальных решений по управлению последними. При совершенствовании транспортной работы по доставке лесных грузов потребителям, большое значение имеет время простоя автомобильного транспорта при погрузочно-разгрузочных операциях, типы и виды погрузочноразгрузочных средств, графики их работы. Следующий момент, который позволяет оперативно реагировать на изменение потребностей в лесных грузах у потребителей, это сохранение и расширение производственных связей между поставщиками лесных грузов, лесными складами и потребителями. Важным этапом при определении целесообразности поставки лесных грузов является информация о производственных мощностях потребителя промежуточной продукции 